\title{
Multilocus differentiation and population structure in a selfer, wild emmer wheat, Triticum dicoccoides
}

\author{
Edward M. Golenberg* $\dagger \ddagger$ and \\ Eviatar Nevo*
}

* Institute of Evolution, University of Haifa, Haifa 31 999, Israel.

$\dagger$ Dept. of Ecology and Evolution, S.U.N.Y. at Stony

Brook, Stony Brook, New York 11794, U.S.A.

Collections of wild emmer wheat, Triticum dicoccoides, were sampled from 5 sites along an 8 kilometre transect and analysed electrophoretically at seven enzymatic loci and phenotypically at one coleoptile pigment locus. Gametic phase disequilibrium coefficients indicate two major eight locus genotypes and one major recombinant type in the area. The multilocus genotypes are distributed in a step cline with the recombinant genotype being found at the interface between the two genotypes. Analysis of the spatial distribution of genotypes in the one polymorphic population suggests that gene flow by either seed or pollen dispersal must be extremely limited. These observations are briefly discussed in the light of previous reports of high gametic phase disequilibrium in inbreeding plant species.

\section{INTRODUCTION}

Gene products within living organisms interact in such a way that the effects of different alleles of a gene are a function not only of its gene product but also of the genetic background in which it is found (Lewontin, 1974; Dykhuizen and Hartl, 1980). In natural populations, selection, genetic drift, non-random matings, migration, founder effects, hitchhiking, and mutation can generate associations between alleles at different loci (Hedrick, 1982). Reproduction without recombination allows the perpetuation of favourable multilocus genotypes, and as a result, non-recombining lineages may, under certain circumstances, be at a selective advantage over recombining lineages. Essentially this argument has been explored in relation to the evolution of asexual vs. sexual reproduction (Williams, 1975; Maynard-Smith 1978), and has been applied in the analyses of asexual populations (Hebert, 1974; Mitter et al., 1979). High levels of inbreeding in sexual populations also effectively reduce recombination between loci (Golding and Strobeck, 1980), and can lead to the perpetuation of gene associations in the absence of actual linkage. In general, the

Present address: $\ddagger$ Department of Botany and Plant Sciences, University of California, Riverside, California 92521, U.S.A. maintenance of gene associations in large equilibrium populations is a function of recombination and epistasis. As the number of loci involved increases the conditions necessary for the maintenance of associations (gametic phase disequilibria, $D \neq 0$ ) at equilibrium become more relaxed (Slatkin, 1972). In addition, when many loci are involved several stable equilibria with $D \neq 0$ may exist (Hastings, 1985).

Gametic phase disequilibria, however, have not been commonly found in natural populations of animals (Barker, 1979; Hedrick et al., 1978; Langley et al., 1977). In contrast, striking examples of gametic phase disequilibrium have been found in highly selfing plant populations (Brown, 1984; Brown, 1979). Unfortunately, these exceptions are confined to only three species, Avena barbata (Clegg and Allard, 1972; Allard et al., 1972; Hamrick and Allard, 1972; Hamrick and Holden, 1979), Hordeum vulgare-H. spontaneum (Clegg et al., 1972; Weir et al., 1972; Weir et al., 1974; Brown et al., 1977), and Phaseolus lunata (Harding and Allard, 1969). Whether or not this is a common phenomenon in inbreeding species in general must be confirmed only after more species have been tested. Here, we report the distribution of multilocus genotypes and gametic phase disequilibria occurring along a transect in natural populations of Triticum dicoccoides, wild emmer wheat in Israel. 


\section{MATERIALS AND METHODS}

Triticum dicoccoides is a primary component of stable open grasslands of the Fertile Crescent. It grows sympatrically with other grasses such as the annuals Avena sterilis, and Hordeum spontaneum and the perennial Hordeum bulbosum. In areas of its range characterised by mild, wet Mediterranean winters, $T$. dicoccoides covers large patches with robust morphs. It is of special interest, being the wild progenitor of cultivated hardwheats (genome $\mathrm{AABB}$ ) and the tetraploid ancestor of modern hexaploid breadwheats (genome AABBDD) (Zohary, 1969; Feldman, 1976).

From a previous study (Nevo et al., 1982), two collections from the Golan heights (Qazrin and Yehudiyya) were identified in which seven electrophoretic loci and one coleoptile pigment locus were fixed for alternative alleles. The two sites are separated by 8 kilometres and are both on a basaltic flow plain. There is a gradual, continuous rise in altitude north-east from Yehudiyya to Qazrin of about 300 metres. The dominant vegetation in both areas are the grasses Avena sterilis and Hordeum bulbosum, although in the area of Yehudiyya, there is an oak park-forest belt of Quercus itheburensis. The trees gradually decrease in number and eventually disappear in the area between the two sites.

In May 1980, a collecting transect was made between these two sites and three intermediate sites were sampled at intervals of 2 to 3 kilometres (fig. 1). Within each collecting site, plants were sampled at intervals of approximately 1 metre with one spike collected per plant. The collected heads were numbered sequentially so that their spatial relation was maintained.

At least two seeds from each spike were germinated and seedlings grown to about a ten day stage. Coleoptile colour, noting the presence or absence of anthocyanins, was recorded for each plant. Fresh leaf tissue was electrophoresed on horizontal starch gels. The electrophoretic procedures may be found in Brown et al. (1978) with the exception of peptidase in which phenylalanyl-alanine was used as a substrate instead of leucyl-alanine. The gels were stained and analysed for seven enzymatic systems: malate dehydrogenase-1 (MDH-1), indophenol oxidase (IPO), 6-phosphogluconic acid dehydrogenase-2 (6-PGDH-2), beta-glucosidase $(\beta$-GLU), peptidase-1 (PEPT-1), and hexokinase (HK). An additional system anodal to the peptidase-1 system of our previously published results was recorded and identified by the name peptidase3 (PEPT-3). The linkage relations between the loci encoding these enzymes have been determined in a separate study (Golenberg, 1986a). Mdh-1 and $H K$ are probably located on chromosome 1 (assuming homology with the $T$. aestivum $\mathrm{A}$ and $B$ chromosomes) and have a recombination fraction of $0 \cdot 19 \pm 0 \cdot 10$. Pept-1, Pept-3, and Ipo all had significant interaction with $R c$ (red coleoptile locus); however, only Pept-1 and $R c$ ( $\mathrm{rf}=0.28 \pm$ 0.07 ) have a recombination fraction significantly different from 0.5 . Both Pept-1 and $R c$ have been located on chromosome 6 in T. aestivum (Golenberg, 1986b; Sutka, 1977).

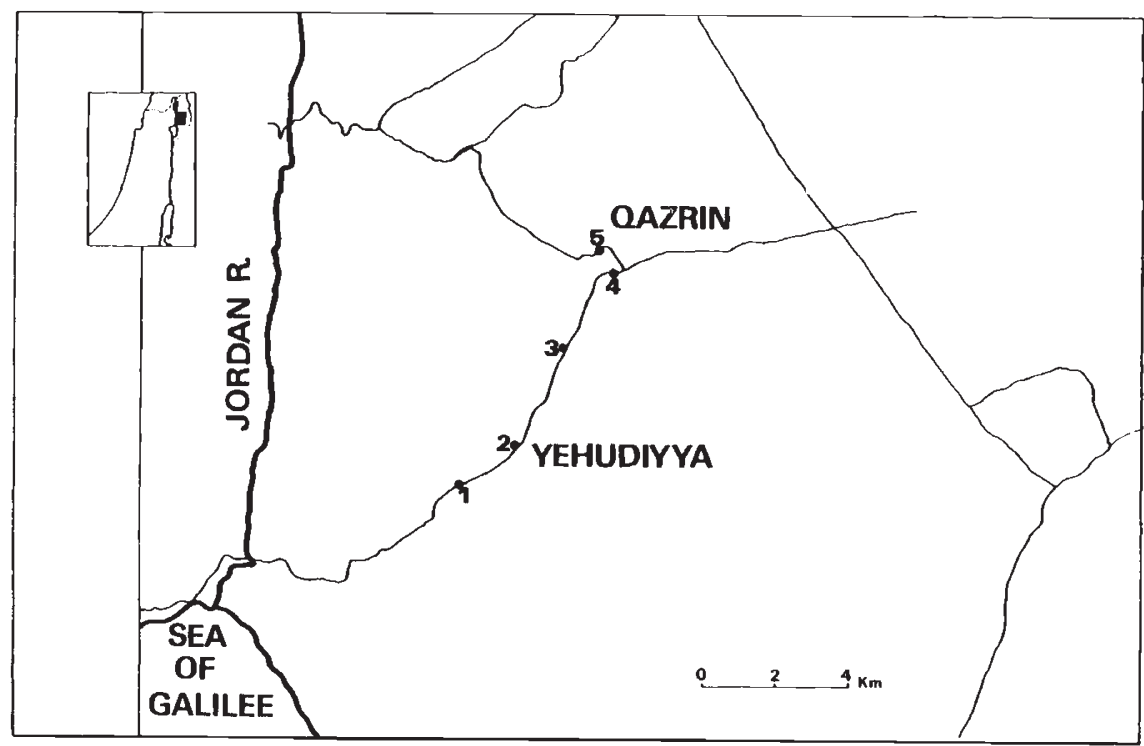

Figure 1 Location of collection sites in Northern Israel. 
Each allozyme system had two alleles and was scored using a binary code, where 1 and 0 correspond to the fast and slow electromorphs respectively. In those systems where apparently only one of the two genomes contributed to the scorable activity, as was inferred from the banding patterns of the variant alleles (6-PGDH-2, IPO, $\beta$-GLU, $\mathrm{HK}$ ), the genotypes were recorded as if they were diploid. Coleoptile pigment was similarly recorded. The zymograms of PEPT-1, PEPT-3, and $\mathrm{MDH}-1$ consisted of two distinguishable contributions. One genomic product was conservative (monomorphic) in all individuals tested, while the second varied. For matters of simplicity, the monomorphic contribution was ignored in scoring. Thus all systems were scored using a simple binary system. In addition, nearly all individuals were homozygous in all loci so that the genotype at a given locus was signified by one number alone (e.g., $1=F F)$. Those loci that were heterozygous were signified by the symbol *. Allele frequencies were determined for each locus for each site. Gametic phase disequilibria were calculated and tested for significance in site 3. Disequilibria values, $D$, were calculated from gametic frequencies (Hedrick et al., 1978; Hill 1974) which could be determined because of the high degree of homozygosity in the wheat due to its high degree of selfing.

\section{RESULTS}

Between 42 and 50 seed spikes were sampled in each population and tested for all the loci mentioned above. Table 1 lists the allozyme and coleoptile pigment frequencies for each collection in the transect. Collections at sites 1 and 2 are fixed or nearly fixed for one allele in all eight loci. In a similar manner, but for the alternative allele, populations 4 and 5 are monomorphic or nearly so. (For simplicity of discussion, the common genotype at sites 1 and 2 will be called Yehudiyya-type and at 4 and 5, Qazrin-type). Collection 3 is clearly in the interface between these two genetic regimes. It is essentially identical in allelic composition to the Qazrin genotype in the loci encoding for PEPT-1, and 6-PGDH-2, but is a mixture of the two regimes in the remaining six loci, being composed of 53-56 per cent Yehudiyya-type and 44-47 per cent Qazrin-type.

The data may be arranged in terms of the eight locus genotypic frequencies in order to assess population structure. By maintaining the order of loci listed in table 1, the Qazrin genotype may be designated as (00001111) and the Yehudiyya genotype as (11110000). Fig. 2 is a histogram of the frequencies of the two common genotypes over the five population sites. On the level of multilocus units, the distribution of genotypes sharply shifts at site 3. Only one individual of the Yehudiyya genotype occurs in collection 3. As opposed to this, 44 per cent of collection 3 consists of Qazrin genotypes. The large proportion of Yehudiyyatype allozymes in MDH-1, IPO, $\beta$-GLU, PEPT-3, $\mathrm{HK}$, and the absence of coleoptile pigment is contributed by an extensive representation of the genotype (11100100), an apparent recombinant.

The spatial distribution of the genotypes in the within site transect of site 3 is presented in fig. 3 .

Table 1 Allozyme allelle frequencies by population (sample size given in parenthesis)

\begin{tabular}{|c|c|c|c|c|c|c|}
\hline \multirow[b]{2}{*}{ Loci } & \multirow[b]{2}{*}{ Allele } & \multirow[b]{2}{*}{$1(46)$} & \multicolumn{3}{|c|}{ Population } & \multirow[b]{2}{*}{$\begin{array}{l}\text { Qazrin } \\
5(49)\end{array}$} \\
\hline & & & $\begin{array}{l}\text { Yehudiyya } \\
2(50)\end{array}$ & $3(50)$ & $4(49)$ & \\
\hline \multirow[t]{2}{*}{$M d h-1$} & 1 & $1 \cdot 00$ & $1 \cdot 00$ & 0.56 & & \\
\hline & 0 & & & 0.44 & $1 \cdot 00$ & $1 \cdot 00$ \\
\hline \multirow[t]{2}{*}{ Ipo } & 1 & $1 \cdot 00$ & $1 \cdot 00$ & 0.54 & 0.02 & \\
\hline & 0 & & & 0.46 & 0.98 & $1 \cdot 00$ \\
\hline \multirow[t]{2}{*}{$\beta-G l u$} & 1 & 1.00 & 1.00 & 0.53 & & 0.02 \\
\hline & 0 & & & 0.47 & $1 \cdot 00$ & 0.98 \\
\hline \multirow[t]{2}{*}{ Pept-1 } & 1 & 0.99 & 1.00 & 0.02 & 0.02 & 0.01 \\
\hline & 0 & 0.01 & & 0.98 & 0.98 & 0.99 \\
\hline \multirow[t]{2}{*}{ Pept-3 } & 1 & 0.03 & & 0.46 & $1 \cdot 00$ & $1 \cdot 00$ \\
\hline & 0 & 0.97 & $1 \cdot 00$ & 0.54 & & \\
\hline \multirow[t]{2}{*}{ 6-Pgdh-2 } & 1 & & & 0.98 & $1 \cdot 00$ & $1 \cdot 00$ \\
\hline & 0 & $1 \cdot 00$ & 1.00 & 0.02 & & \\
\hline \multirow[t]{2}{*}{$H k$} & 1 & 0.03 & 0.04 & 0.45 & $1 \cdot 00$ & $1 \cdot 00$ \\
\hline & 0 & 0.97 & 0.96 & 0.55 & & \\
\hline \multirow[t]{2}{*}{$R c$} & 1 & 0.01 & & 0.45 & $1 \cdot 00$ & $1 \cdot 00$ \\
\hline & 0 & 0.99 & $1 \cdot 00$ & 0.55 & & \\
\hline
\end{tabular}




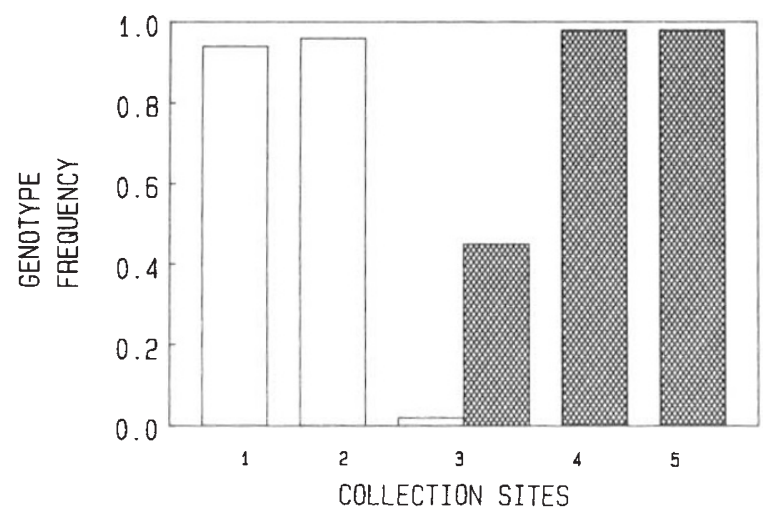

Figure 2 Histogram of the frequency of Yehudiyya (11110000) (open bars) and Qazrin (00001111) (solid bars) genotypes by collection sites.

The multilocus genotypes are listed sequentially in the order in which the spikes were sampled in the field transect. The distribution of genotypes is nonrandom. Qazrin-type plants (genotype 00001111) are flanking (positions 1-14 and 44-50) a very extensive recombirant patch (plants 15-43) of approximately 28 metres width. Within the recombinant patch, only four non-(11100100) plants are found: position 29 (11010100), position 32 (00001111 Qazrin-type), position 40 (11110000 Yehudiyya-type), and position $43(10 * 001 * * 0)$.

The disequilibrium coefficients for the eight loci in collection 3 are listed in table 2 . The disequilibrium coefficients indicate two associated groups of loci in collection 3 . One group consists of Pept-1 and 6-Pgdh-2, and the other consists of the six loci $M d h-1, I p o, \beta-G l u, P e p t-3, H k$, and $R c$. All of these associations are significant at a level of $P<0.001$. As reported above, $M d h-1$ and $H k$ are linked on chromosome 1. Ipo, Rc, Pept-1, and Pept-3 also have shown significant interactions in an $F_{2}$ population after crossing. (Golenberg,
$1986 a$ ). These groups are not strictly preserved in the collection 3 data. Pept-1 is not associated with Ipo or $R c$. Alternatively, loci showing a highly significant association, such as Pept-1 and 6-Pgdh2 , Ipo and $\beta$-Glu, etc. are not derived from the abovementioned possible linkage groups, but from potentially independently assorting loci (Golenberg, 1986a).

\section{DISCUSSION}

Multilocus associations have been previously reported in the predominantly selfing grasses Avena barbata (Allard et al., 1972; Clegg and Allard, 1972; Hamrick and Holden, 1979; Kahler et al., 1980), Hordeum vulgare (Clegg et al., 1972), and Hordeum spontaneum (Brown et al., 1980). In the Avena studies, particular associations of genotypes to environments suggesting the existence of xeric and mesic multilocus genotypes were reported on both fine and coarse scales (Allard et al., 1972; Hamrick and Holden, 1979). These findings were highly suggestive of selection acting on a coadapted complex. Similarly, selection for particular associations was suggested in the barley studies, especially in light of the development of similar genotypes deriving from independent populations (Clegg et al., 1972). Hedrick and Holden (1979) have criticised these interpretations by suggesting that hitchhiking of neutral loci linked to selected loci may be effective in generating the disequilibria observed in these highly selfed populations. Brown (1984) further warns that, in general, highly selfed species can generate disequilibria between neutral loci when population sizes are low based on the findings of Golding and Strobeck (1980).

In Triticum dicoccoides, the distribution of the multilocus genotypes is discontinuous, abruptly

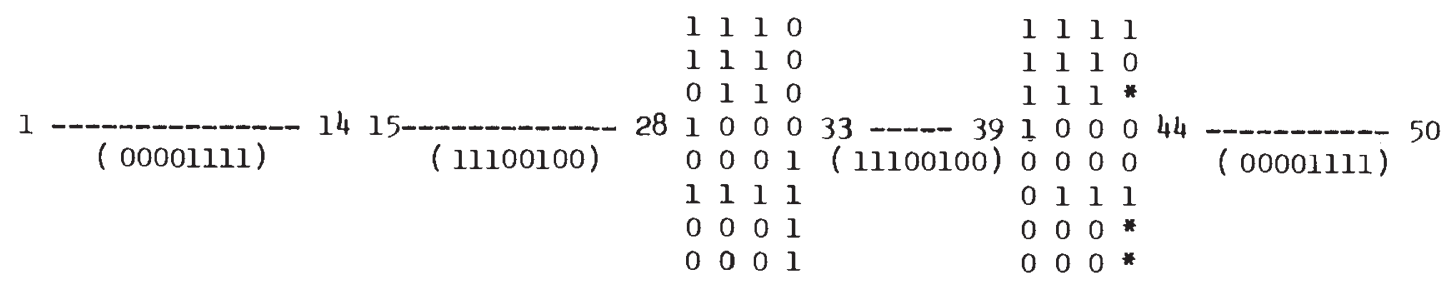

Figure 3 Distribution of genotypes within the 50 metre transect in Site 3. Genotypes are listed sequentially in the order that the spikes were collected in the field. The resulting distribution thus represents the spatial order of genotypes along the collection transect in Site 3. 
Table 2 Gametic phase disequilibria between paired loci in population $3 D=X_{11}-p_{1} q_{1}$ (Hill, 1974)

\begin{tabular}{|c|c|c|c|c|c|c|c|}
\hline & Ipo & $\beta-G l u$ & Pept-1 & Pept-3 & 6-Pgdh-2 & $H k$ & $R c$ \\
\hline $\begin{array}{l}\text { Mdh-1 } \\
\text { Ipo } \\
\beta-G l u \\
\text { Pept-1 } \\
\text { Pept-3 } \\
\text { 6-Pgdh-2 } \\
\text { Hk }\end{array}$ & $0.2376 \#$ & $\begin{array}{l}0.2232 \# \\
0.2338 \#\end{array}$ & $\begin{array}{l}0.0088 \\
0.0092 \\
0.0094\end{array}$ & $\begin{array}{l}-0 \cdot 2376 \# \\
-0 \cdot 2284 \# \\
-0 \cdot 2438 \# \\
-0 \cdot 0092\end{array}$ & $\begin{array}{c}-0 \cdot 0088 \\
-0 \cdot 0092 \\
-0 \cdot 0094 \\
-0 \cdot 0196 \# \\
0 \cdot 0092\end{array}$ & $\begin{array}{l}-0.2430 \# \\
-0.2430 \# \\
-0.2385 \# \\
-0.0090 \\
0.2330 \# \\
0.0090\end{array}$ & $\begin{array}{l}-0.2430 \# \\
-0.2430 \# \\
-0.2385 \# \\
-0.0090 \\
0.2330 \# \\
0.0090 \\
0.2475 \#\end{array}$ \\
\hline
\end{tabular}

$\#=P<0.001$.

switching from Yehudiyya to Qazrin genotypes in the area of site 3. Unfortunately, in contrast to the Avena studies, no clear associations with particular environmental components can be ascertained. The gradual change in vegetation along the transect noted above does reflect, however, underlying micro-climatic changes, with the lower sites being warmer. Indeed, it has been shown that these collections of $T$. dicoccoides are differentiated phenologically and track the climatic gradient (Golenberg, submitted). When grown under standardised greenhouse conditions, plants from site 1 took 82.6 days until the appearance of the first awns, plants from site 2 took 110.0 days and plants from site 5 took 135.9 days, on average. Additional time until appearance of the second awn also differed significantly and reflected a response to a limited time window for reproduction. Such differentiation and tracking indicates that these populations of wild emmer are not recent introductions to their sites and that within multilocus classes (collections 1 and 2, Yehudiyya type) ecologically important genetic variation does occur. Thus, it is apparent that these multilocus genotypes are at least associated with selectable traits which are themselves associated with the environment. However, the relationship between these genotypes and these traits remains only tentative at this point, and does not directly shed light on the mechanisms maintaining the multilocus distribution as it appears today.

Outcrossing in wild emmer is quite limited (estimated $\mathrm{t}^{\sim 0.005}$, Golenberg, submitted) and, therefore, recombination is expected to be very small. On the other hand, dispersal distances are harder to measure since they will reflect pollen flow in cases of rare outcrosses, and seed dispersal over space and time. The distribution of genotypes at site 3 indicates, however, that gene flow may be quite limited. The patch of recombinant genotypes as defined from individuals 15 through 43 is sharply delimited. There is no indication of mixing of individuals of the parental Qazrin genotype at the ends of the patch. The appearance of the Qazrin genotype at position 32,12 metres from the edge of the patch, may be a result of relatively long range dispersal or may be a relict of a previous, more extensive occurrence of the parental genotype within the patch. It clearly is an exceptional occurrence. So too, the single sampling of a recent outcross at position 43 occurs at the immediate interface between the Qazrin (11110000) and recombinant (11100100) patches. While this evidence cannot be used to estimate average dispersal distance, the general indication is that dispersal distances or genetic neighbourhoods are limited to a scale of several metres.

The behaviour of clines, in general, and multilocus clines, in particular, has been studied in relation to selection per locus, recombination, and dispersal distances for randomly mating populations (Endler, 1977; Barton, 1983). The sharpness of a cline is generally a function of strong selection and/or limited dispersal distances. The analysis of multilocus systems modifies these findings by showing that effective selection coefficients may be higher than individual selection coefficients on a single locus if recombination is limited. Furthermore, in the case of an existing multilocus cline, barrier effects may enhance the evolution of further differentiation.

In light of these theoretical findings and the observations reported herein, we may expect that the slope of multilocus clines in $T$. dicoccoides to be quite sharp and the width of introgression to be limited. In order to determine the dimensions of the recombinant zone in this species, intensive sampling on the scale of tens of metres would be necessary. Secondly, we may expect to see the addition of neutral or even deleterious alleles to existing multilocus genotypes once initial differentiation has become established. The localisation of many rare alleles in these two areas (Nevo et al., 1982) may be a reflection of this process. 
Acknowledgements We would like to thank Prof. R. K. Koehn for his generous donation of laboratory space and equipment, and to Prof. D. Futuyma and Dr Batia Lavie for commenting on an earlier version of this manuscript. We are indebted to the Israel Discount Bank Chair of Evolutionary Biology, the Wolfson Foundation, to the Ancell-Teicher Research Foundation for Genetic and Molecular Evolution established by Florence and Theodore Baumritter of New York, for financial support. This is contribution No. 608 in Ecology and Evolution from the State University of New York at Stony Brook.

\section{REFERENCES}

ALLARD, R. W., BABBEL, G. R., CLEGG, M. T. AND KAHLER, A. L. 1972. Evidence for coadaptation in Avena barbata. Proc. Nat. Acad. Sci. (U.S.A.), 69, 3043-3048.

BARKER, J. S. F. 1979. Inter-locus interactions: A review of experimental evidence. Theoret. Pop. Biol., 16, 323-346.

BARTON, N. H. 1983. Multilocus clines. Evolution, 37, 454-471. BROWN, A. H. D. 1979. Enzyme polymorphism in plant populations. Theo. Pop. Biol., 15, 1-42.

BROWN, A. H. D. 1984. Multilocus organization of plant populations. In Wohrmann, K. and Loeschocke, L. (eds.) Population Biology and Evolution, Springer-Verlag, Berlin.

BROWN, A. H. D., NEVO, E. AND ZOHARY, D. 1977. Association of alleles at esterase loci in wild barley, Hordeum spontaneum. Nature, 268, 430-431.

BROWN, A. H. D., NEVO, E., ZOHARY, D. AND DAGAN, O. 1978. Genetic variation in natural populations of wild barley (Hordeum spontaneum). Genetica, 49, 97-108.

BRoWN, A. H. D., FELDMAN, M. W. AND NEVO, E. 1980. Multilocus structure of natural populations of Hordeum spontaneum. Genetics, 96, 523-536.

CleGG, M. T. AND ALlARD, R. W. 1972. Patterns of genetic differentiation in the slender wild oat species Avena barbata. Proc. Nat. Acad. Sci. U.S.A., 69, 2472-2478.

CleGG, M. T., Allard, R. W. AND KAHLER, A. L. 1972. Is the gene the unit of selection? Evidence from two experimental plant populations. Proc. Nat. Acad. Sci., 69, 2472-2478.

DYKHUIZEN, D. AND HARTL, D. L. 1980. Selective neutrality of 6-Pgd allozymes in E. coli and the effects of genetic background. Genetics, 96, 801-817.

ENDLER, J. A. 1977. Geographic Variation, Speciation and Clines, Princeton University Press. Princeton, New Jersey.

FELDMAN, M. 1976. Wheats. Simmonds, N. W. (ed.) In Evolution of Crop Plants, Longman Ltd, London, pp. 120-128.

GOLDING, G. B. AND STROBECK, C. 1980. Linkage disequilibrium in a finite population that is partially selfing. Genetics, 94, 777-789.

GOLENBERG, E. M. 1986a. Linkage relationships in wild emmer wheat, Triticum dicoccoides. Genetics, 114, 1023-1031.

GOLENBERG, E. M. 1986b. Chromosomal location of peptidase, Pept-1, genes in Triticum aestivum var Chinese Spring. Genet. Res., 48, 19-20.

HAMRICK, J. L. AND ALLARD, R. W. 1972. Microgeographical variation in allozyme frequencies in Avena barbata. Proc. Nat. Acad. Sci. USA, 69, 2100-2104.
HAMRICK, J. L. AND HOLDEN, L. R. 1979. Influence of microhabitat heterogeneity on gene frequency distribution and gametic phase disequilibrium in Avena barbata. Evolution, 33, 521-533.

HASTINGS, A. 1985. Four simultaneously stable polymorphic equilibria in two-locus two-allele models. Genetics, 109, 255-261.

HEBERT, P. N. C. 1974. Ecological differences between genotypes in a natural population of Daphnia magna. Heredity, 33, 327-337.

HARDING, J. AND ALLARD, R. w. 1969. Population studies in predominantly self-pollinated species. XII. Interactions between loci affecting fitness in a population of Phaseolus lunatus. Genetics, 61, 721-736.

HEDRICK, P. W. 1982. Genetic hitchhiking: A new factor in evolution? BioScience, 32.11, 845-853.

HEDRICK, P. W. AND HOLDEN, L. 1979. Hitchhiking: An alternative to coadaptation for the barley and slender wild oat examples. Heredity, 43, 79-86.

HEDRICK, P. W., JAIN, S. AND HOLDEN, L. 1978. Multilocus systems in evolution. Evolutionary Biology, 11, 101-182.

HILL, W. G. 1974. Estimation of linkage disequilibrium in randomly mating populations. Heredity, 33, 229-239.

KAHLER, A. L., ALLARD, R. W., KRZAKOWA, M., WEHRLAHN, C. F. AND NEVO, E. 1980. Associations between isozyme phenotypes and environment in the slender wild oat (Avena barbata) in Israel. Theor. Appl. Genet., 56, 31-47.

LANGLEY, C. H., ITO, K. AND VOELKER, R. A. 1977. Linkage disequilibrium in natural populations of Drosophila melanogaster: Seasonal variation. Genetics, 86, 447-454.

LEWONTIN, R. C. 1974. The Genetic Basis of Evolutionary Change, Columbia University Press, New York.

MAYNARD-SMITH, J. 1978. The Evolution of Sex, Cambridge University Press, Cambridge.

MitTER, C., FUTUYMA, D. J., SCHNEIDER, J. C. AND HARE, J. D. 1979. Genetic variation and host plant relations in a parthenogenetic moth. Evolution, 33, 777-790.

NEVO, E., GOLENBERG, E., BEILES, A., BROWN, A. H. D. AND ZOHARY, D. 1982. Genetic diversity and environmental associations of wild wheat, Triticum dicoccoides, in Israel. Theo. Appl. Genet., 62, 241-254.

SLATKIN, M. 1972. On treating the chromosome as the unit of selection. Genetics, 72, 157-168.

SUTKA, J. 1977. The association of genes for purple coleoptile with chromosomes of the wheat variety Mironovskaya 808 . Euphytica, 26, 475-479.

WEIR, B. S., ALLARD, R. W. AND KAHLER, A. L. 1972. Analysis of complex allozyme polymorphisms in a barley population. Genetics, 72, 505-523.

WEIR, B. S., ALLARD, R. W. AND KAHLER, A. L. 1974. Further analysis of complex allozyme pólymorphisms in a barley population. Genetics, 78, 911-918.

Williams, G. C. 1975. Sex and Evolution. Princeton University Press, Princeton, N.J.

ZOHARY, D. 1969. The progenitors of wheat and barley in relation to domestication and agricultural dispersal in the Old World. In Ucko, P. J. and Dimbleby, G. W. (eds.) The Domestication and Exploitation of Plants and Animals, Duckworth, London, pp. 47-66. 